child is not a miniature adult. The relatively large head of the child in relation to the small body size, coupled with developmental differences, increases the vulnerability of the child's head to injury, for example a higher incidence of axonal shearing injuries than in adults.

Other aspects of injury control worth learning by developing countries from industrialized countries include:

- The scientific basis for injury control research, which is likely to be updated from time to time

- Peer identification of all persons involved in injury control research

- Public involvement in the injury control process

- Use of multisectoral and intersectoral cooperative efforts for injury control

- The formation of regional task forces on injury control to facilitate and advocate

- The standardization of injury data and methods to permit comparisons

- Inclusion of the science of injury control in health curricula, for example medical schools

- Increased use of the Internet

- Establishment of centers for injury research, control, and policy

- The organization of regional conferences on injury prevention and control.

Nevertheless, I agree that it is very dangerous for developing countries to copy blindly and adopt all the countermeasures for injuries developed largely in industrialized countries. For example, it would be ridiculous for developing countries to try to import expensive intensive care unit technologies when many emergency departments in these countries barely have enough supplies or staffing. On the other hand, copying technologies like the use of helmets by motorcyclists, which has been proven effective in industrialized countries, is the right thing to do. In fact, motorcycle helmet use is being utilized effectively in many developing Asian countries and saves many dear lives. We can also learn much from the failures in injury control from the industrialized world which, I believe, are as valuable as the many success stories.

1 De Haven H. Mechanical analysis of survival in falls from heights of fifty to one hundred and fifty feet. War Med 1942; 2: 586-96.

2 Press E. Epidemiologic approach to accident prevention. $\mathrm{Am}$ f Public Health 1948; 38: 1442-5.

3 Gordon JE. The epidemiology of accidents. Am 7 Public Health 1949; 39: 504-15.

4 Gibson JJ. The contribution of experimental psychology to the formulation of the problem of safety: a brief for basic research. Reprinted from: Behavioral approaches to accident research. New York: New York Association for the Aid of Crippled Children, 1961: 77-89.

5 Haddon W Jr. On the escape of tigers: an ecologic note. $A m \mathcal{F}$ Public Health 1970; 60: 2229-34.

6 Haddon W Jr. Advances in the epidemiology of injuries as a basis for public policy. Public Health Rep 1980; 95: 411-21.

7 Spiegel CN, Lindaman FC. Children can't fly: a program to prevent childhood morbidity and mortality from window falls. Am $\mathcal{F}$ Public Health 1977; 67: 1143-7.

8 Smith GS, Barss P. Unintentional injuries in developing countries: the epidemiology of a neglected problem. Epidemiol Rev 1991; 13: 228-66.

9 Baker SP, O'Neill B, Ginburgh MJ, Li G. The injury fact book. New York: Oxford University Press, 1992

10 US Department of Justice, Bureau of Justice Statistics. Crime victimization in the United States. Washington, DC: US Department of Justice, 1993.
Health Economics and Financing Programme, Health Policy Unit, London School of Hygiene and Tropical Medicine, Keppel Street, London WC1E 7HT, UK

Correspondence to: Dr Zwi.

\title{
Injury control in developing countries: context more than content is crucial
}

\author{
Anthony B Zwi
}

Injury prevention and control has, in recent decades, made considerable strides in a number of industrialised countries. Forjuoh draws attention to many of these and recommends that lessons from the successful application of injury interventions be applied in low and middle income countries.

$\mathrm{He}$ is right: there is much experience that can benefit others; resources are scarce and should not be wasted. But, while there is no doubt that countries can learn from each other, considerable caution should be exercised in assuming the applicability and relevance of injury control policies in vastly different contexts.

Consider the content of injury control policy, the context in which it is formulated and implemented, the processes through which this is done, and the actors involved. In seeking to generalise lessons from one setting to another, the content of injury control interventions is least likely to be contentious: establishing what works and applying these interventions where possible is seen as the priority. But even here, there may be difficulties in transposing effective interventions between settings. Take the example of traffic safety. Dinesh Mohan, one of the leading proponents of appropriate injury control policy in low and middle income countries, argues that the extremely rapid growth of vehicle stock in South East Asia, the mix between different types of transport (motorised and unmotorised, including animal drawn, and 
the range of vehicles including two, three, and four wheeled) pose traffic safety challenges that have not previously been faced anywhere.

Segregating different modes of transport, for example, may intuitively appear reasonable but may have negative effects: vehicles travelling at much higher speeds and thereby greatly increasing the incidence of crashes and the resulting injuries. Interventions have to be modified for the local setting, and need to integrate educational, engineering, environmental, and legislative efforts. The scope for such an integrated range of interventions is always present, but opportunities are much reduced by scarce resources.

Even well established interventions may not have as profound an effect when transferred to other settings. Although the effectiveness of seat belts has been well demonstrated, they will not make as significant an impact on reducing traffic related fatalities in situations where pedestrians represent the greatest proportion of vehicle crash victims. The relative risk of injury associated with not wearing a seat belt may be similar in both high and low income settings, but the attributable risk will be much lower in poorer countries where pedestrians are the majority of road victims. Improvements to the environment in which vehicles are operated, and to the safety of public transport vehicles and systems, may represent more important priorities for injury inventions.

The constraints posed by the context in which policy is developed and implemented in poorer countries must be recognised. Their per capita spending on health is a fraction of the $\$ 400-\$ 2500$ in the industralised world. Limited human, material, and infrastructural resources, as well as low literacy levels and poor access to media impede the implemention of policy. Well trained injury prevention personnel are scarce. This hinders the adoption, and more importantly the adaptation of good ideas from elsewhere. For example, a country such as Zimbabwe, which has committed itself to diminishing the burden of injuries, still has difficulty mobilising resources to ensure that most of the needed tasks are performed.

Gender relations, and attitudes to, and perception of, violence against women, for example, will be context-specific; simply applying interventions against violence developed in one setting to another, be it in the north or south, will fail.

Developing context-specific interventions that are cheaper and more cost effective will be a major challenge to workers in low and middle income countries. The challenge of mobilising further resources at national level will not be won simply by the availability of scientific evidence (some of which may derive from other countries), but will require attention to integrating scientific insights with those of economics and politics.

Attention should also be focused on the key actors involved with health policy initiatives in low and middle income countries. Especially in the poorest countries, international agencies play a prominent part in influencing health policy priorities and in supporting their implementation. New approaches to setting priorities, such as the measurement of DALYS (disability adjusted life years), however imperfect, may provide valuable opportunities for raising the profile of injuries in children and young adults.

Securing the support of international agencies and donors, as well as expatriate and local non-governmental organisations, may enhance the chances of injury-related policies being developed in resource-constrained countries. Some low and middle income countries may allow more ready access to policy makers and more rapid decision making: an advantage which should be used. More evidence than in wealthy countries may be demanded to demonstrate the value of interventions in terms of cost effectiveness, efficiency, equity, sustainability, and accessibility. Researchers should anticipate these needs and begin to address them.

To stimulate any action at all, issues have to win their place on the policy agenda - they have to be perceived to be important and to be deserving of, or necessitating, a response. At any one time there are dozens of issues competing for the attention of policy makers. Many health problems in low and middle income countries are perceived to be priorities; intentional and unintentional injuries have yet to secure their place among those demanding a coherent response.

Despite all these differences, there is still scope for learning, as Forjuoh argues. Important lessons from industrialised country successes and failures may not be generally agreed but include: devote attention to upstream interventions and reduce exposure to hazardous agents and situations at source; ensure equity is highlighted in policy decisions; stress population based rather than individual based interventions; involve all actors in building powerful coalitions and alliances across sectors; ensure that the evidence for interventions is well established; integrate scientific with economic, political, moral and cultural concerns; recognise the different perspectives of researchers and policy makers and formulate creative means of stimulating dialogue and exchange between them; collect data at all stages of the policy process; link concerns with injury with others of relevance to the community such as safety and security, development, human rights, consumer protection, environment, and accountable government. In summary, it is through seeing the broader picture, not just the content of injury control, that significant advances will be made.

The research upon which this discussion was based was funded by the Overseas Development Administration of the UK. However, the Overseas Development Administration can accept no responsibility for any information provided or views expressed. The author acknowledges insights related to the policy process gained from colleagues both in the Ministry of Health and Child Welfare in Zimbabwe and from the Health Policy Unit at the London School of Hygiene and Tropical Medicine. 